\title{
ADAPTIVE VALUE OF RESPIRATORY ADJUSTMENTS TO SHUNT HYPOXIA AND TO ALTITUDE HYPOXIA 1
}

\author{
BY GEORGE HUSSON 2 AND A. B. OTIS: \\ (From the Department of Surgery, The Johns Hopkins University School of Medicine, \\ Baltimore, Md.)
}

(Submitted for publication July 30, 1956; accepted August 26, 1956)

Only a few adaptive mechanisms by which the body responds to hypoxia are at present understood well enough to be quantitatively examined and evaluated. Among these are the alterations that occur in the pulmonary ventilation, the acid base balance of the blood and the oxygen carrying capacity of the blood. It is the purpose of this paper to compare the adaptive value of these adjustments, as judged by their effectiveness in raising the partial pressure of oxygen in blood and tissues, in two types of hypoxia 1) that arising from chronic exposures to a low $\mathrm{P}_{\mathrm{O}_{2}}$ in the environment (altitude hypoxia) and 2) that arising from the presence of a right to left shunt in the circulation (shunt hypoxia). We shall attempt to show that although the changes which occur in these two types of hypoxia are qualitatively similar in some respects, there are important quantitative differences in their adaptive value. We shall also present evidence that in the case of shunt hypoxia there is no reduction in the basal oxygen requirement of the body. For previous work by other authors pertinent to our general subject see references 1 through 4 . More detailed data and a description of methods used in this investigation may be found in references 5 through 8.

\section{Pulmonary ventilation}

Numerous investigators have shown that individuals who are chronically hypoxic from prolonged residence at high altitudes have an increased ventilation which is greater the higher the altitude. There is evidence in the literature that

1 This study was supported by funds provided under contract AF 18(600)-342 with the USAF School of Aviation Medicine, Randolph Field, Texas.

2 Present address : Department of Pediatrics, Syracuse Memorial Hospital, Syracuse 10, New York.

${ }^{3}$ Present address: College of Medicine, University of Florida, Gainesville, Florida. individuals who are hypoxic because of circulatory shunts also ventilate more than normal.

We have measured the total resting ventilation of individuals with shunt hypoxia and have confirmed the presence of hyperventilation (6). In a smaller number we have made measurements of the resting alveolar ventilation. The results are shown as points in Figure 1. For comparison a curve previously published by Rahn and Otis (9) and indicating the magnitude of alveolar ventilation as a function of alveolar $\mathrm{P}_{\mathrm{O}_{2}}$ in healthy individuals who had lived at altitude for relatively extended periods is also shown. Although our data show a rather large variation among individuals

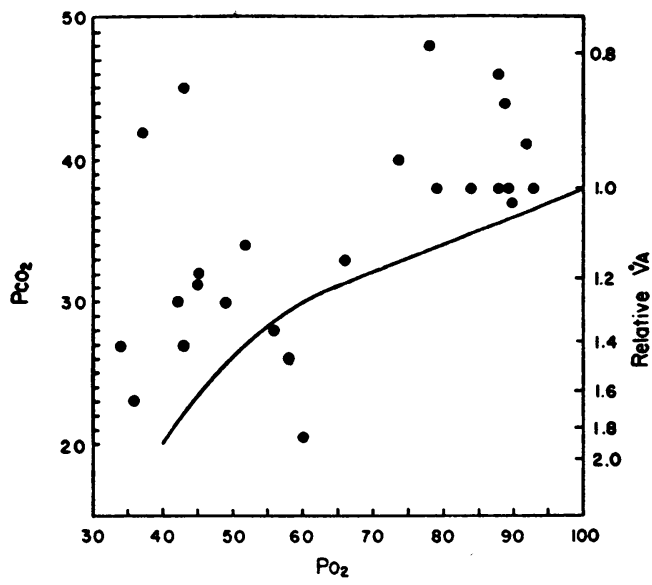

Fig. 1. Alveolar Pooz and Relative Alveolar Ventillation as a Function of Arterial $\mathrm{P}_{\mathrm{O}_{2}}$

The solid circles represent measurements made on patients with congenital heart disease. Those with a $P_{O_{2}}$ less than $75 \mathrm{~mm}$. had right to left circulatory shunts, those with a $\mathrm{P}_{2}$ greater than $75 \mathrm{~mm}$. did not. The alveolar $\mathrm{Pco}_{2}$ was either directly determined from analysis of end tidal samples or calculated from expired $\mathrm{P}_{\mathrm{CO}_{2}}$ and estimated dead space. The curve is taken from Rahn and Otis (9) and applies to normal individuals acclimatized to various altitudes. Relative alveolar ventilation was calculated as follows :

$$
\dot{\mathrm{V}}_{\mathrm{A}}=\frac{38 \mathrm{~mm}}{\mathrm{P}_{\mathrm{AOO}}}
$$


they demonstrate a definite tendency for the alveolar ventilation to increase with decreasing arterial $\mathrm{P}_{\mathrm{O}_{2}}$, the relationship being similar in form but less in extent to that found for the altitude dwellers.

The hyperpnea of the altitude dweller constitutes for him an important adaptation. If at 15,000 feet, for example, an individual did not increase his ventilation above the sea level value, his alveolar (and arterial) $\mathbf{P}_{\mathbf{O}_{2}}$ would be about 38 $\mathrm{mm}$. Hg. His arterial oxygen saturation would be about 72 per cent. The increase in ventilation that usually occurs in the individual acclimatized to this altitude is such as to increase his arterial $\mathrm{PO}_{\mathrm{O}_{2}}$ to about $50 \mathrm{~mm}$. $\mathrm{Hg}$ and his arterial saturation to about 83 per cent, an increase which is really significant as an adaptive mechanism.

The victim of shunt hypoxia on the other hand, can increase the oxygenation of his arterial blood but little by hyperpnea. His pulmonary venous blood will be about 97 per cent saturated even with a normal ventilation; and although increasing the ventilation will raise the $\mathrm{P}_{\mathrm{O}_{2}}$ of this blood, it will alter the per cent saturation only insignificantly be-

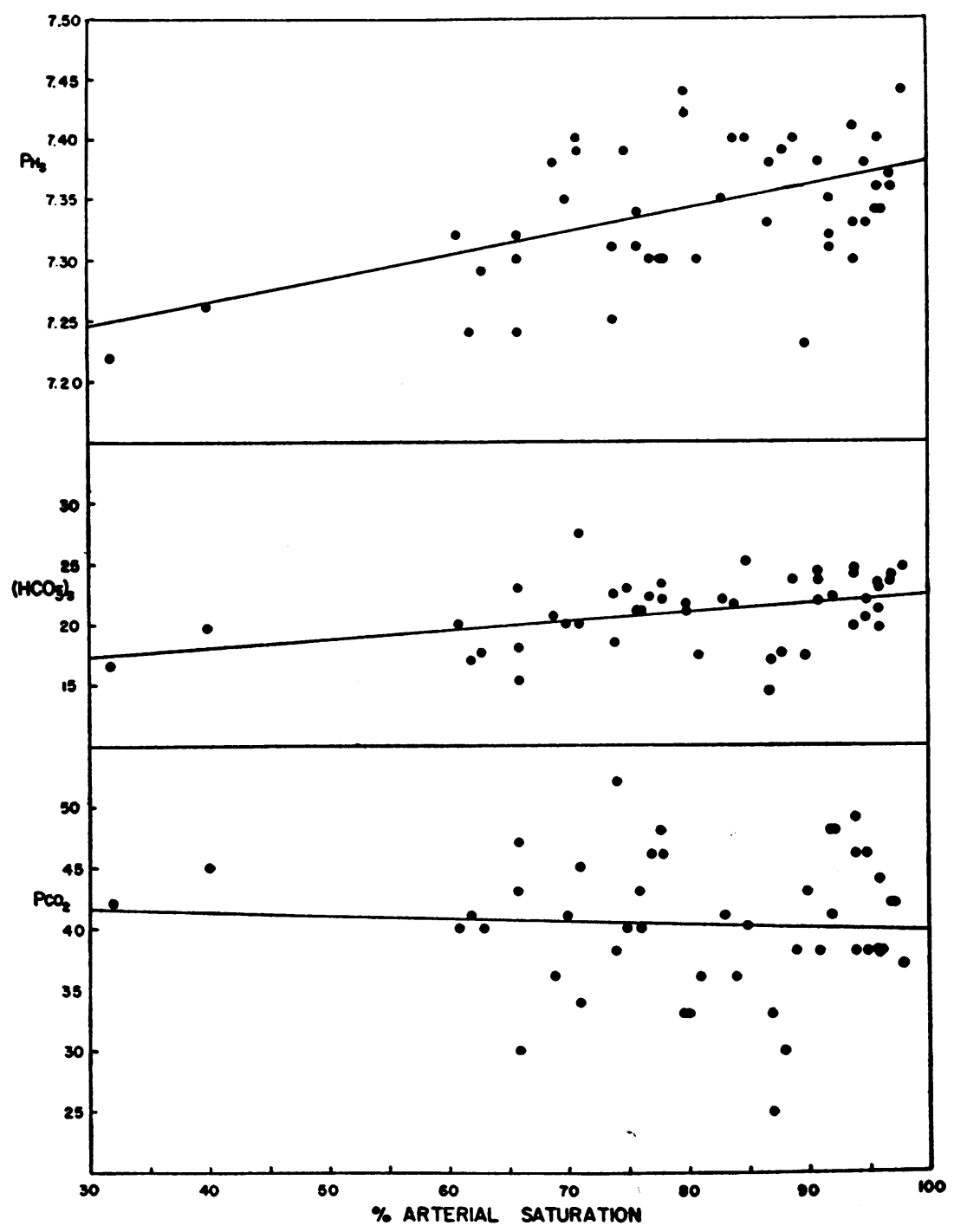

Fig. 2. Plasma pH, Plasma Bicarbonate Concentration in Mimimols per Litrer and Partial Pressure of Carbon Dioxide in Arterial Blood as a Function of Arterial Oxygen Saturation 
cause of the flatness of the dissociation curve in this region. Furthermore that component of this mixed arterial blood which is shunted around his lungs will not be directly affected at all. Resting hyperpnea in such an individual would therefore seem to be of negligible adaptive value as far as improvement of oxygenation of his systemic arterial blood is concerned.

However, the presence of a right to left shunt introduces a problem in $\mathrm{CO}_{2}$ elimination as well as of oxygen uptake. With a normal resting ventilation the pulmonary venous $\mathrm{P}_{\mathrm{CO}_{2}}$ will be normal but the arterial $\mathrm{P}_{\mathrm{CO}_{2}}$ will be higher and arterial $\mathrm{pH}$ lower than normal because of the admixture of venous blood. A normal arterial $\mathrm{P}_{\mathbf{C O}_{2}}$ and $\mathrm{pH}$ can be maintained only by hyperventilation of the proper magnitude. With no increase in ventilation a normal $\mathrm{pH}$, but elevated $\mathrm{P}_{\mathrm{CO}_{2}}$, could be maintained by an increase in the alkaline reserve. It is therefore of interest to know exactly how the acid base balance is adjusted in shunt hypoxia.

\section{Acid base balance}

We have measured arterial $\mathrm{pH}$, and plasma bicarbonate and have calculated the arterial $\mathrm{P}_{\mathrm{CO}_{2}}$ in 35 individuals with shunt hypoxia and in 12 nonhypoxic individuals. The results are shown in Figure 2 in which each of the above variables is plotted as a function of the arterial $\mathrm{O}_{2}$ saturation. The following regression lines have been calculated.

$$
\mathrm{pH}=0.00189 \text { ( } \% \text { Sat. })+7.19
$$

Std. error of estimate $=0.05$

$$
\left(\mathrm{HCO}_{3}\right)=0.074 \text { (\% Sat.) }+15.09
$$

Std. error of estimate $=2.54$

$$
\mathrm{P}_{\mathrm{CO}_{2}}=42.23-0.0234 \text { ( } \% \text { Sat.) }
$$

Std. error of estimate $=5.4$

The interrelationship among these variables is graphically presented in Figure 3 on the pH-bicarbonate diagram of Davenport (10). The data are widely scattered and values from the nonhypoxic and hypoxic groups overlap to some extent but the points representing the hypoxic group tend to fall in the region of the chart below the normal $\mathrm{pH}$ and below the normal buffer line, and so indicate metabolic acidosis.

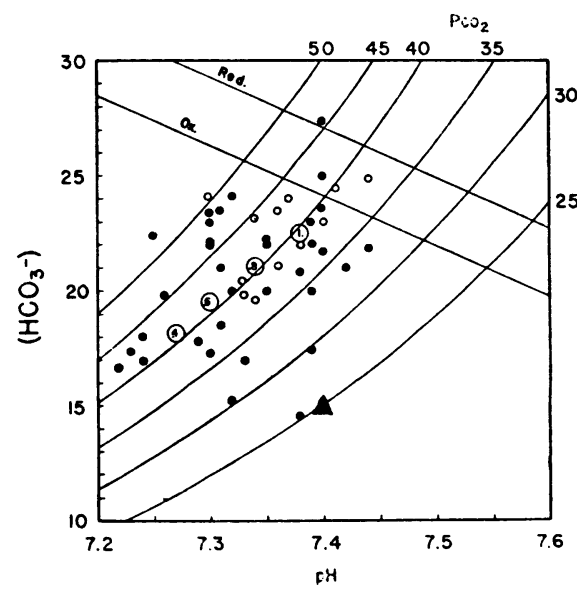

Fig. 3. Relationship between Plasma Bicarbonate (MILlimols PER Liter), $\mathrm{PH}$ ANd $\mathrm{P}_{\mathrm{CO}_{2}}$ MM. Hg

Closed circles represent subjects with and open circles subjects without shunt hypoxia. The lines labelled red. and ox. are standard dissociation curves from Davenport (10).

The large circles on the chart labelled 1.0, 0.8, $0.6,0.4$ are calculated from the regression equations for 100 per cent, 80 per cent, 60 per cent, and 40 per cent saturation, respectively, and their position indicates a tendency for metabolic acidosis to increase progressively with hypoxia. The position of the triangle represents the acid-base picture of residents at high altitude who have a per cent saturation of about 75 (11). There is no doubt that the average congenital cyanotic individual in our group has a different acid-base adjustment than the altitude dweller with a similar degree of hypoxia.

Figure 2 indicates that the alkali reserve of individuals with shunt hypoxia tends to be reduced in proportion to the degree of hypoxia but to a less extent and for a different reason than is that of altitude dwellers who are chronically hypoxic to a similar degree. Our subjects tend to maintain an alveolar $\mathrm{P}_{\mathrm{CO}_{2}}$ of about $40 \mathrm{~mm}$. on the average, whereas the hypoxic altitude dweller has a much lower $\mathrm{P}_{\mathrm{CO}_{2}}$. Consequently, the average congenital cyanotic individual appears to be in a state of metabolic acidosis which is only partially compensated by an increased ventilation. Such a tendency toward metabolic acidosis in congenitally cyanotic individuals has been reported previously by Morse and Cassells (12). 
The acid-base picture in chronic altitude hypoxia is, by contrast, one of compensated respiratory alkalosis. This situation enables the mountain dweller to load his arterial blood at a relatively high $\mathrm{P}_{\mathbf{O}_{2}}$ and at the same time to maintain a normal $\mathrm{pH}$.

Although the mechanisms and the sequence of events involved in the acid-base adjustments to altitude hypoxia seem reasonably well understood, the same cannot be said for the individual who is hypoxic from congenital heart disease. It is not clear, for example, why the respiratory center does not respond sufficiently to relieve the acidosis that tends to be present in these individuals. Regardless of its origin it may be that an acidosis is of advantage to the congenital cyanotic because it would tend to aid in the unloading of oxygen in the tissues without hindering to a comparable degree the loading of oxygen in the lungs. Reference to the nomograms of Dill, Talbott, Consolazio, and Edwards $(11,13)$ will make this clear.

Consider an individual whose arterial saturation is 65 per cent because of the presence of a right to left shunt. The blood leaving his lungs will be almost completely saturated (say 97 per cent) whatever the $\mathrm{pH}$, since the Bohr effect is very small at high saturations. If the $\mathrm{pH}$ of the mixed arterial blood beyond the shunt were 7.4 the $\mathrm{P}_{\mathrm{O}_{2}}$, at 65 per cent saturation, would be $34 \mathrm{~mm}$. On the other hand if the $\mathrm{pH}$ were 7.25 , the $\mathrm{P}_{\mathrm{O}_{2}}$ at the same saturation would be $39 \mathrm{~mm}$. The $\mathrm{P}_{\mathrm{o}_{2}}$ of mixed venous blood leaving the tissue would be affected to about the same degree, and we may conclude that the presence of the acidosis resulted in delivery of $\mathrm{O}_{2}$ to the tissues at a pressure about $5 \mathrm{~mm}$. higher than would have occurred at a normal $\mathrm{pH}$.

Thus it appears that the acidosis observed in some congenital cyanotic individuals may be considered as an advantageous adaptation insofar as delivery of $\mathrm{O}_{2}$ to the tissues is concerned, although it may of course be disadvantageous in other regards.

One might ask whether acidosis would similarly be of benefit in altitude hypoxia. The answer seems to be that it would not, because in the hypoxia of high altitude the blood leaving the lungs is at a relatively low saturation and the Bohr effect would hinder the loading of $\mathrm{O}_{2}$ in the lungs sufficiently to offset any advantage to unloading in the tissues.

This can be illustrated by a specific example again with reference to Dill, Talbott, and Consolazio's (11) nomogram. Consider an individual at altitude, who has an oxygen carrying capacity of 30 volumes per cent, who is ventilating at such a rate that his arterial $P_{\mathrm{O}_{2}}$ is $33 \mathrm{~mm}$., and whose A-V oxygen difference is 5 volumes per cent. At $\mathrm{pH} 7.4$ the arterial saturation will be 65 per cent and the mixed venous saturation 48 per cent corresponding to $\mathrm{P}_{\mathrm{O}_{2}}$ 's of $33 \mathrm{~mm}$. and $25 \mathrm{~mm}$., respectively. At $\mathrm{pH} 7.25$ the arterial saturation will be 56 per cent and the mixed venous saturation 40 per cent corresponding to $\mathrm{P}_{\mathrm{O}_{2}}$ 's of 33 and $25 \mathrm{~mm}$., respectively. Thus an acidosis is evidently of no advantage to the delivery of $\mathrm{O}_{2}$ in the case of altitude hypoxia.

\section{The increase in oxygen carrying capacity with chronic hypoxia}

It is well known that individuals who are chronically hypoxic tend to develop a polycythemia with a concomitant increase in the oxygen carrying capacity of the blood. The mechanism by which the increased hemoglobin is brought about is still obscure, nor is there general agreement as to its importance in the overall picture of acclimatization (14).

Data showing the magnitude of the increase in oxygen carrying capacity of the blood in man residing at various altitudes have been summarized by Hurtado (15). In Figure 4 we have plotted these data to show the oxygen carrying capacity as a function of the per cent saturation of the arterial blood. It is evident that an excellent linear relationship exists, the equation for the straight line being

$$
\mathrm{C} \max =67.1-0.476 \mathrm{Sa},
$$

where $\mathrm{C} \max$ is the oxygen carrying capacity in volumes per cent and $\mathrm{Sa}$ is the per cent saturation of arterial blood.

The combined $\mathrm{O}_{2}$ carried by the arterial blood is the product of capacity times saturation or in this case

$$
\mathrm{CaO}_{2}=67.1 \mathrm{Sa}-0.476 \mathrm{Sa}^{2} .
$$

Values for combined oxygen have also been plotted on Figure 4 as well as a curve calculated 


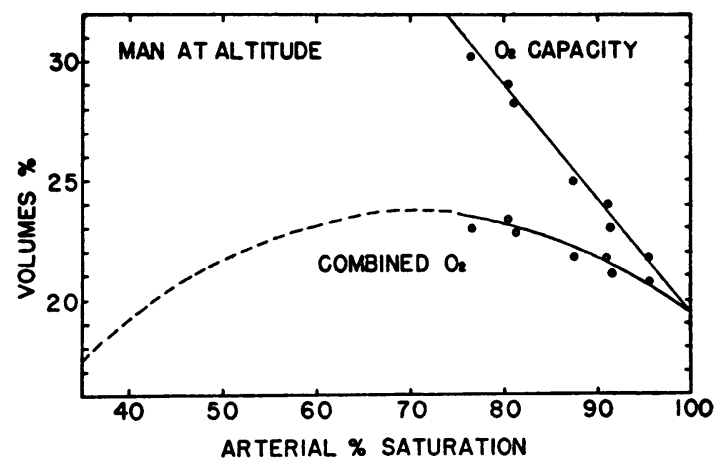

Fig. 4. Combined Oxygen and Oxygen Carrying Capactity as a Function of Arterial Saturation in Altitude Dwellers

from Equation 2 and extrapolated to lower saturations than those for which data are available. Differentiation of Equation 2 with respect to Sa and setting the result equal to 0 shows that the combined oxygen has a maximal value at a saturation of 70.5 per cent.

This means that when man is chronically exposed to hypoxia the combined oxygen in his arterial blood will actually increase, because of the increased carrying capacity, until the hypoxia is so severe as to cause a saturation of 70 per cent. It is interesting in this connection that man does not live permanently at altitudes at which the arterial saturation lies below this value.

We have collected a number of our own measurements relating oxygen carrying capacity and per cent saturation of arterial blood which were

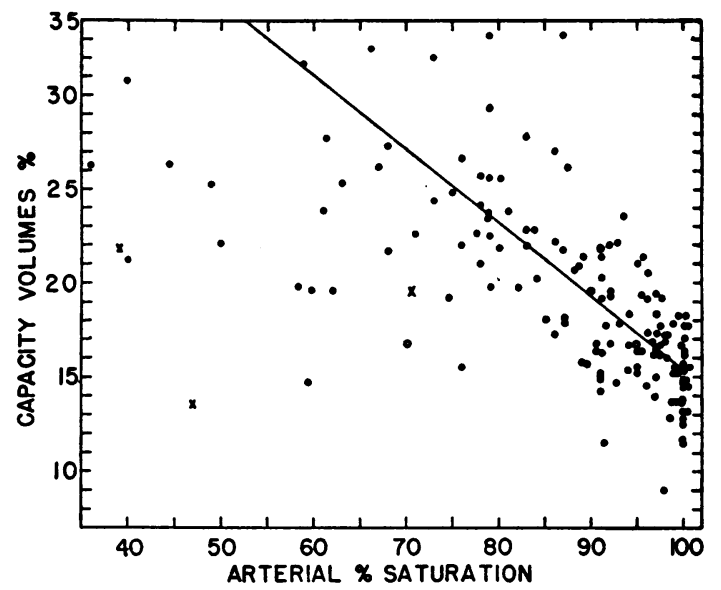

Fig. 5. Oxygen Carrying Capacity as a Function of Arterial Saturation in Patients Studied in this INVESTIGATION made on 142 patients, many of whom were hypoxic because of a right to left circulatory shunt. Figures 5 and 6 show that the relationships between capacity and per cent saturation and combined oxygen and per cent saturation are somewhat similar to those observed for the altitude dweller.

The straight line in Figure 5 was fitted to the points representing saturations of 75 per cent or above, and conforms to the equation

$$
\mathrm{C} \max =54.3-0.39 \mathrm{Sa} \text {. }
$$

The curved line in Figure 6 was derived from the straight line in Figure 5 and is represented by the equation

$$
\mathrm{CaO}_{2}=54.28 \mathrm{Sa}-0.39 \mathrm{Sa}^{2} .
$$

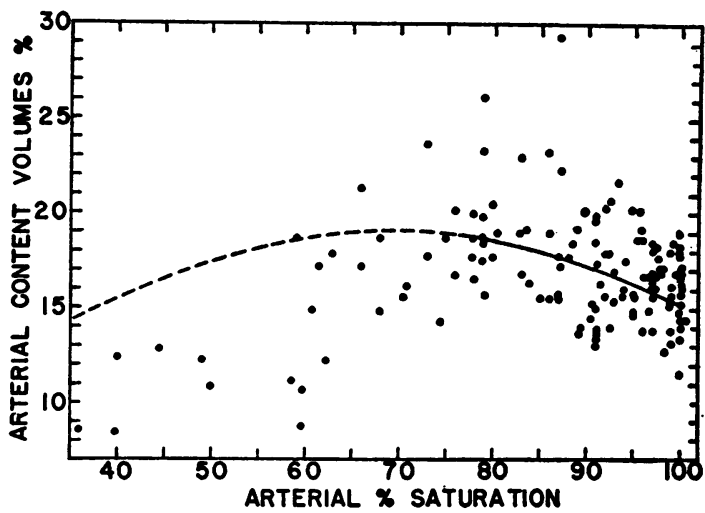

Fig. 6. Combined Oxygen in the Arterial Blood of Pattents Studied in This Investigation

This curve passes through a maximum at a saturation of 69.6 per cent.

In Figure 5 it is interesting that the points representing saturations less than 70 per cent fall for the most part below the straight line. This suggests the possibility that hypoxia more severe than that represented by a saturation of 70 per cent fails to stimulate any further increase in hemoglobin.

The importance of the increased $\mathrm{O}_{2}$ combining power of the blood to the delivery of $\mathrm{O}_{2}$ to the tissues in chronic hypoxia

The mountain dweller gains from an increased oxygen capàcity because removal of a given amount of oxygen from the blood by the tissues produces less of a drop in the saturation and consequently the venous $\mathrm{P}_{\mathrm{O}_{2}}$ will be higher than it 
would be otherwise. The arterial $\mathrm{P}_{\mathrm{O}_{2}}$, since it is determined almost solely by the ventilation, will not be affected by an increased oxygen combining power of the blood.

The individual with shunt hypoxia will gain even more than the altitude dweller from an increased oxygen capacity, because in his case both arterial and venous $\mathrm{P}_{\mathrm{O}_{2}}$ 's will be elevated. The following example will make this clear.

First consider a normal individual who is exposed to an altitude such that his arterial saturation is 75 per cent, whose oxygen carrying capacity is 20 volumes per cent, and whose oxygen consumption and cardiac output are such that his arterio-venous oxygen difference is 5 volumes per cent. His mixed venous saturation in this case will be 50 per cent. By reference to the $\mathrm{O}_{2}$ dissociation curve and application of the Barcroft formula 4 (16) we can estimate his arterial, mixed venous, and mean tissue capillary $\mathrm{P}_{\mathrm{O}_{2}}$ 's to be 40 , 27 and $31 \mathrm{~mm}$. $\mathrm{Hg}$, respectively.

Now let this same individual increase his $\mathrm{O}_{2}$ capacity to 30 volumes per cent leaving his ventilation, $\mathrm{O}_{2}$ consumption and cardiac output as before. His arterial saturation will remain 75 per cent, but the content will have increased from 15 to 22.5 volumes per cent. The mixed venous content will be $22.5-5=17.5$ volumes per cent. The mixed venous saturation will be $17.5 / 30=$ 58 per cent. The arterial, mixed venous and mean tissue capillary $\mathrm{P}_{\mathrm{O}_{2}}$ 's will be 40,31 and $34 \mathrm{~mm}$., respectively. Thus the increased oxygen capacity has increased the mean capillary $\mathrm{P}_{\mathrm{O}_{2}}$ by only 3 $\mathrm{mm} . \mathrm{Hg}$.

Let us now consider an individual at sea level with an $\mathrm{O}_{2}$ capacity of 20 volumes per cent but with a right to left circulatory shunt such that his arterial blood is composed of a mixture of equal parts of blood that has passed through the lungs and of mixed venous blood. Let his cardiac output and oxygen consumption be such that his arterialvenous difference is 5 volumes per cent. We can consider the blood that has passed through his lungs as essentially 100 per cent saturated and to have an oxygen content of 20 volumes per cent.

\footnotetext{
- Barcroft's (16) equation is as follows: Mean tissue capillary $\mathbf{P}_{\mathrm{O}_{2}}=$ Venous $\mathbf{P}_{\mathrm{O}_{2}}+\frac{\text { Arterial } \mathbf{P}_{\mathrm{O}_{2}}-\text { Venous } \mathbf{P}_{\mathrm{O}_{2}}}{3}$.
}

We can write two simultaneous equations as follows :

$$
\begin{aligned}
& \mathrm{C}_{2 \mathrm{O}_{2}}-\mathrm{C}_{\nabla \mathrm{O}_{2}}=5 \text { vols. } \%, \\
& \mathrm{C}_{\mathrm{aO}_{2}}=\frac{\mathrm{C}_{\nabla \mathrm{O}_{2}}+20 \text { vols. } \%}{2} .
\end{aligned}
$$

Solving those equations we find that arterial content is 15 volumes per cent and mixed venous content is 10 volumes per cent. The corresponding saturations are 75 per cent and 50 per cent, the same as in the case of the normal individual at altitude, and the arterial, mixed venous and mean capillary $\mathrm{P}_{\mathrm{O}_{2}}$ 's will likewise be identical with those of the individual at altitude.

Now let us consider the above individual with the same cardiac output, $\mathrm{O}_{2}$ consumption and degree of venous admixture but with his $\mathrm{O}_{2}$ capacity increased to 30 volumes per cent. We can write the following simultaneous equations:

$$
\begin{aligned}
& \mathrm{C}_{\mathrm{aO}_{2}}-\mathrm{C}_{\mathrm{VO}}=5 \text { vols. } \%, \\
& \mathrm{C}_{\mathrm{O}_{2}}=\frac{\mathrm{C}_{\mathrm{VO}}+30 \text { vols. } \%}{2} .
\end{aligned}
$$

Solution of these equations and conversion of contents to saturations give us a saturation of 83 per cent for the arterial and 67 per cent for the mixed venous blood and $\mathrm{P}_{\mathrm{O}_{2}}$ 's of 49,35 , and 40 $\mathrm{mm}$. $\mathrm{Hg}$ for arterial, mixed venous and mean tissue capillary $\mathrm{P}_{\mathrm{O}_{2}}$. Thus the increased $\mathrm{O}_{2}$ capacity has raised the mean capillary $\mathrm{P}_{\mathrm{O}_{2}}$ from 31 to 40 mm., a gain of $9 \mathrm{~mm}$., as compared with a gain of $3 \mathrm{~mm}$. for the individual at altitude.

\section{Resting $\mathrm{O}_{2}$ consumption in shunt hypoxia}

It would undoubtedly be a useful adaptation to a state of chronic hypoxia if the body could find a means of carrying on its basal activities with a diminished consumption of oxygen. That such an adaptation may actually occur was suggested by Bing, Vandam, Handelsman, Campbell, Spencer, and Griswold (1) who reported that in 28 of 30 patients who were chronically hypoxic from congenital cyanotic heart disease (Tetralogy of Fallot) the basal metabolism was either significantly below or at the lower limits of normal. Values for the basal metabolic rate as low as -48 were recorded and the average for the group was -23 . 
In contrast to these striking results normal or slightly elevated values for basal oxygen consumption in congenital cyanotic heart disease have been obtained by Holling and Zak (17), Burchell, Taylor, Knutson, and Wood (18), Ernsting and Shephard (2) and Davison, Armitage, and Arnott (4). Thus the majority of the evidence indicates that no diminution in basal oxygen requirement occurs in chronic hypoxia resulting from congenital cyanotic heart disease, but the question is of such fundamental importance that we decided to satisfy our curiosity by measurements of our own.

None of the above mentioned investigators made measurements of oxygen consumption on a control group of acyanotic individuals but used "standard values" for comparison. Consequently, for our own investigation we decided to include a suitable control series.

Our chronically hypoxic series consisted of 42 individuals with cyanotic congenital heart disease. The arterial oxygen saturation in this group ranged from 61 per cent to 93 per cent and averaged 83 per cent. Our control series was composed of 45 individuals with non-cyanotic congenital heart disease, and arterial oxygen saturations of 94 per cent or higher. Various age groups were represented in both series. The measurements of oxygen consumption were made in connection with the procedure of cardiac catheterization which was being performed for diagnostic purposes. The subjects, who were in a fasting state, had received shortly before the procedure premedication consisting of morphine sulfate, 1 mg. per $5 \mathrm{Kg}$. body weight and scopalamine, 0.05 to $0.1 \mathrm{mg}$. per $5 \mathrm{Kg}$. body weight, and in the age groups up to 15 years Nembutal suppositories, $2 \mathrm{mg}$. per $\mathrm{Kg}$. body weight. The patients over 15 years usually received Nembutal ${ }^{\oplus}$ orally in a dose of $0.1 \mathrm{gm}$. Oxygen consumption measurements were based on the analysis of expired gas collected in a 100-liter recording spirometer. After two or three preliminary wash-out periods, the final collection was made during a 3-minute period. Analysis of the expired gas was performed on the Scholander (19) apparatus. Body surface area was estimated from height and weight according to Dubois (20). Oxygen saturation was determined by a modification of the Nahas (21) technique on blood samples drawn by arterial puncture.

\section{RESULTS}

Since it is well known that the resting oxygen consumption per square meter of surface area varies considerably with age, allowance for this was made in the interpretation of our data. The subjects in each series (acyanotic and cyanotic) were divided into five age groups and the mean oxygen consumption was determined for each group. The results are represented graphically in Figure 7. Data from Robinson (22) for the resting oxygen consumption of normal males of comparable ages are also shown for comparison.

It is clear that up to age 20 our data for both the cyanotic and acyanotic series agree remarkably well with those of Robinson. In the higher age groups, however, our values, while still showing no significant difference between cyanotic and acyanotic patients, deviate significantly from those of Robinson's. We are not certain as to the explanation for this discrepancy, but offer the suggestion that the older age groups were not as completely relaxed during the procedure partly perhaps because of less effective sedation and partly because of greater apprehension arising from more awareness of the potential hazards of cardiac catheterization.

At any rate, the important fact from the point of view of the present investigation is that there is no significant difference between the oxygen con-

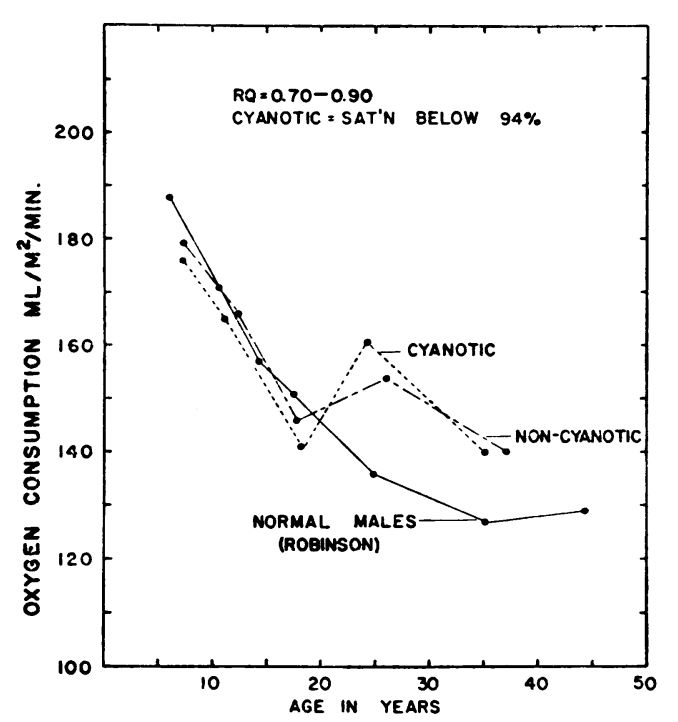

Fig. 7. Relationship Between Resting Oxygen Consumption and Age in Cyanotic and Non-Cyanotic Subjects 
sumption of patients with chronic hypoxia arising from circulatory anomalies and that of those who had circulatory anomalies but no hypoxia. This is true whether the comparison is made between the two series as a whole or between similar age groups from the two series.

We have also compared our two series in another fashion on the basis of basal metabolic rates estimated by application of the Dubois (20) nomogram to our measured values for oxygen consumption. This comparison shows that, although in each series there is a slightly higher than normal B.M.R. value, the difference between the two series is not significant.

From this study we can only infer that the resting oxygen requirement is not depressed in our chronically hypoxic subjects and so are in agreement with the majority of other investigators mentioned in the introduction, and at variance with the findings of Bing, Vandam, Handelsman, Campbell, Spencer, and Griswold (1). Whether the low values for oxygen consumption obtained by Bing mean that his hypoxic subjects were vastly different from those studied by others or whether they were due to some systematic difference in his technique of measurement is a question that cannot be answered. Only one of our subjects had a B.M.R. as low as the average of Bing's group. Possibly Bing's subjects were more heavily sedated during the test, but no mention of sedation is made in his published reports. The objection might be raised that our cyanotic subjects were, on the average, less hypoxic than were Bing's, and that one therefore might expect less of a depression of metabolism in our group. This argument appears weak, however, in view of the fact that his data show no significant correlation between degree of hypoxia (as estimated by arterial saturation) and depression of the basal metabolic rate. It is unfortunate that Bing's study did not include measurements on a control group of noncyanotic subjects.

\section{COMMENT}

We have examined only a few of the many bodily adjustments that may occur as a result of exposure to chronic hypoxia, and have evaluated these on the basis of a single criterion, their effectiveness in elevating the $\mathrm{P}_{\mathrm{O}_{2}}$ of the body. Other adjustments may be of equal or even greater importance and other criteria for their evaluation may prove more useful (23).

We have deliberately omitted any consideration of cardiac output because, in the case of shunt hypoxia, there is not sufficient information available as to how an alteration in cardiac output is distributed between systemic and pulmonary flows when a shunt is present $(4,18)$.

Adaptations are, by their nature, compromises in that concessions must be made in return for the advantages gained. For example, there is evidence that polycythemia is a predisposing factor in the formation of pulmonary and cerebral thrombi $(24,25)$. The importance and probability of occurrence of such undesirable effects must of course be taken into account in any complete evaluation of an adaptive mechanism, especially when individual cases are concerned.

\section{SUMMARY}

Although an increased pulmonary ventilation is an important adaptation to altitude hypoxia, it is of negligible value in raising the $\mathrm{P}_{\mathrm{O}_{2}}$ of the body in shunt hypoxia. It may be of importance in the optimal regulation of acid-base balance in the latter instance however. In chronic altitude hypoxia the usual acid-base balance is one of compensated respiratory alkalosis. In shunt hypoxia there is a tendency for metabolic acidosis to be present. This may be of advantage in aiding the unloading of oxygen from blood to tissues. Polycythemia, which is usually present in both altitude and shunt hypoxia, is a more effective adaptation in the latter type because here it can raise the arterial as well as the mixed venous $\mathrm{P}_{\mathrm{O}_{2}}$. The basal oxygen requirement of individuals with shunt hypoxia does not appear to be lower than the normal.

\section{REFERENCES}

1. Bing, R. J., Vandam, L. D., Handelsman, J. C., Campbell, J. A., Spencer, R., and Griswold, H. E., Physiological studies in congenital heart disease. VI. Adaptations to anoxia in congenital heart disease with cyanosis. Bull. Johns Hopkins Hosp., 1948, 83, 439.

2. Ernsting, J., and Shephard, R. J., Respiratory adaptations in congenital heart disease. J. Physiol. 1951, 112, 332. 
3. Holling, H. E., Compensatory mechanisms for the anoxia of cyanotic congenital heart disease. Clin. Sc., 1952, 11, 283.

4. Davison, P. H., Armitage, G. H., and Arnott, W. M., The mechanisms of adaptation to a central venousarterial shunt. Brit. Heart J., 1953, 15, 221.

5. Husson, G. S., and Otis, A. B., Physiological adaptation to chronic hypoxia. A. Resting oxygen consumption. School of Aviation Medicine, USAF, Report No. 55-15, 1955.

6. Husson, G. S., and Otis, A. B., Physiological adaptation to chronic hypoxia. B. Resting pulmonary ventilation. School of Aviation Medicine, USAF, Report No. 55-76, 1955.

7. Husson, G. S., and Otis, A. B., Physiological adaptation to chronic hypoxia. C. Acid-base adjustments. School of Aviation Medicine, USAF, Report No. 56-25, 1956.

8. Otis, A. B., and Husson, G. S., Physiological adaptation to chronic hypoxia. D. Oxygen transport. School of Aviation Medicine, USAF, Report No. 56-26, 1956.

9. Rahn, H., and Otis, A. B., Man's respiratory response during and after acclimatization to high altitude. Am. J. Physiol., 1949, 157, 445.

10. Davenport, H. W., The ABC of Acid-Base Chemistry. The Elements of Physiological Blood-Gas Chemistry for Medical Students and Physicians. 3rd ed., Chicago, The University of Chicago Press, 1950.

11. Dill, D. B., Talbott, J. H., and Consolazio, W. V., Blood as a physicochemical system. XII. Man at high altitudes. J. Biol. Chem., 1937, 118, 649.

12. Morse, M., and Cassells, D. E., Arterial blood gases and acid-base balance in cyanotic congenital heart disease. J. Clin. Invest., 1953, 32, 837.

13. Dill, D. B., Edwards, H. T., and Consolazio, W. V., Blood as a physicochemical system. XI. Man at rest. J. Biol. Chem., 1937, 118, 635.
14. Grant, W. C., and Root, W. S., Fundamental stimulus for erythropoiesis. Physiol. Rev., 1952, 32, 449.

15. Hurtado, H., in Standard Values in Blood, Albritton, E. C., Ed., Philadelphia, W. B. Saunders Co., 1952.

16. Barcroft, J., Features in the Architecture of Physiological Function. Cambridge, England, The University Press, 1934.

17. Holling, H. E., and Zak, G. A., Cardiac catheterization in the diagnosis of congenital heart disease. Brit. Heart J., 1950, 12, 153.

18. Burchell, H. B., Taylor, B. E., Knutson, J. R. B., and Wood, E. H., Circulatory adjustments to the hypoxemia of congenital heart disease of the cyanotic type. Circulation, 1950, 1, 404.

19. Scholander, P. F., Analyzer for accurate estimation of respiratory gases in one-half cubic centimeter samples. J. Biol. Chem., 1947, 167, 235.

20. Dubois, E. F., Basal Metabolism in Health and Disease, 3rd ed., Philadelphia, Lea \& Febiger, 1936.

21. Nahas, G. G., Spectrophotometric determination of hemoglobin and oxyhemoglobin in whole hemolyzed blood. Science, 1951, 113, 723.

22. Robinson, S., Experimental studies of physical fitness in relation to age. Arbeitsphysiol., 1938, 10, 251.

23. Stickney, J. C., and Van Liere, E. J., Acclimatization to low oxygen tension. Physiol. Rev., 1953, 33, 13.

24. Rich, A. R., A hitherto unrecognized tendency to the development of widespread pulmonary vascular obstruction in patients with congenital pulmonary stenosis (Tetralogy of Fallot). Bull. Johns Hopkins Hosp., 1948, 82, 389.

25. Berthrong, M., and Sabiston, D. C., Jr., Cerebral lesions in congenital heart disease. A review of autopsies on one hundred and sixty-two cases. Bull. Johns Hopkins Hosp., 1951, 89, 384. 